\title{
Genetic polymorphisms in folate and homocysteine metabolism as risk factors for DNA damage
}

\author{
Nicoletta Botto ${ }^{* 1,2}$, Maria Grazia Andreassi ${ }^{1}$, Samantha Manfredi ${ }^{1}$, Serena Masetti ${ }^{1,2}$, Franca \\ Cocci $^{3}$, Maria Giovanna Colombo ${ }^{1}$, Simona Storti ${ }^{1}$, Antonio Rizza ${ }^{1}$ and Andrea Biagini ${ }^{1}$
}

${ }^{1}$ CNR, Institute of Clinical Physiology, G Pasquinucci Hospital, Massa, Italy; ${ }^{2}$ Sant'Anna School of University Studies and Doctoral Research, Italy; ${ }^{3}$ CNR, Institute of Clinical Physiology, Pisa, Italy

Epidemiological studies indicated a role for polymorphisms in genes of folate and homocysteine (Hcy) metabolism in the etiology of neurodegenerative disease, congenital defects and coronary artery disease (CAD). This study investigated the effect of several polymorphisms [C677T, A1298C of methylenetetrahydrofolate reductase (MTHFR) and A66G of methionine synthase reductase (MTRR) genes] on Hcy levels and DNA damage in 68 patients who underwent coronary angiography. Plasma Hcy concentrations were higher in patients with multivessel disease with respect to monovessel disease and no-CAD patients $(19.4 \pm 2.6$ vs $11.6 \pm 1.2$ and $13.7 \pm 1.4 \mu \mathrm{mol} / \mathrm{l}$, respectively; $P=0.03)$. 677TT patients had higher Hcy levels than those with $677 \mathrm{CC}$ or $677 \mathrm{CT}$ genotypes $(26.2 \pm 4.3 \mathrm{vs} 13.1 \pm 1.4$ and $13.0 \pm 1.4 \mu \mathrm{mol} / \mathrm{l}$, respectively; $P=0.0006$ ). No significant associations were found between $A 1298 C$ and A66G

polymorphisms and plasma Hcy levels. Among patients with $677 \mathrm{CC}$ genotype, 66CG individuals tended to have higher levels of Hcy than 66AA homozygotes (14.5 \pm 1.9 vs $8.9 \pm 0.7 \mu \mathrm{mol} / \mathrm{l}, P=0.06)$. Multivessel disease patients showed an increased frequency of DNA damage, measured by the micronucleus (MN) frequency, as compared to monovessel disease and no-CAD subjects ( $12.5 \pm 1.1$ vs $8.5 \pm 0.8$ and $8.2 \pm 0.9$, respectively; $P=0.006)$. The $\mathrm{MN}$ were positively correlated with Hcy levels $(r=0.33, P=0.006)$ and were significantly higher in subjects with the 677TT genotype compared with the 677CC or 677CT genotypes (14.4 \pm 2.0 vs $8.8 \pm 1.2$ and $9.5 \pm 0.7$, respectively; $P=0.006)$. A1298C and A66G polymorphisms had no effect on MN frequency. However, among 677TT patients, 66GG subjects tended to have higher levels of MN than those 66AG and 66AA (18.2 \pm 3.6 vs $13.8 \pm 4.0$ and $10.3 \pm 1.7$, respectively; $P=N S)$. Our results indicate that genetic instability may be associated with increased risk for multiple Hcy-related diseases. European Journal of Human Genetics (2003) 11, 671-678. doi:10.1038/sj.ejhg.5201024

Keywords: homocysteine; folate; methylenetetrahydrofolate reductase; methionine synthase reductase; DNA damage; micronucleus test; coronary artery disease

Introduction

Recent evidences have emphasized that both micronutrient deficiencies and genetic variations in enzymes involved in homocysteine (Hcy) metabolism may contribute to an increased risk for coronary artery disease (CAD),

*Correspondence: Dr N Botto, CNR, Institute of Clinical Physiology, G. Pasquinucci Hospital, via Aurelia Sud-Montepepe, 54100 Massa, Italy. Tel: ++39585 493646; Fax ++39585 493601; E-mail: botto@ifc.cnr.it Received 10 December 2002; revised 11 March 2003; accepted 2 April 2003 neural tube defects, several types of cancer and neurodegenerative disease. ${ }^{1-5}$ In the last few years, several common genetic variants affecting Hcy metabolism have been identified.

The methylenetetrahydrofolate reductase (MTHFR) enzyme plays a central role in the metabolism of Hcy. This protein catalyses the conversion of 5,10-methylenetetrahydrofolate to 5-methyltetrahydrofolate, the predominating circulating form of folate and the methyl donor for remethylation of Hcy to methionine. The most common C677T polymorphism, changing alanine to valine in 
position 222, leads to a thermolabile form of MTHFR with reduced enzyme activity. ${ }^{6,7}$ Homozygosity for this $677 \mathrm{~T}$ variant was shown to be associated with increased plasma Hcy levels, particularly when folate status is low, ${ }^{8,9}$ and it has been described as a risk factor for CAD, although this association is not clearly established at present. ${ }^{10}$ Recently, we have demonstrated that the 677TT genotype was also associated with DNA damage in patients with CAD and a positive relation was found between plasma Hcy levels and micronucleus $(\mathrm{MN})$ frequency as well. ${ }^{11}$

A second common polymorphism in the MTHFR gene is a 1298 A to C transition, which leads to a glutamate-toalanine exchange and results in a reduced overall MTHFR specific activity, although to a lesser degree than the C677T mutation. ${ }^{12-14}$ Individuals who are carriers of the $1298 \mathrm{C}$ allele do not appear to have increased Hcy plasma levels; however, combined heterozygotes for both MTHFR mutations might have higher Hcy levels and decreased folate levels, ${ }^{12,13}$ suggesting an interaction between A1298C and C677T polymorphisms in determining elevated Hcy levels. Consistent with the lack of association with plasma Hcy, the A1298C polymorphism alone is not associated with increased risk for CAD. ${ }^{15,16}$

Methionine synthase reductase (MTRR) that acts maintaining adequate levels of activated cobalamin, an intermediate methyl carrier during the methionine synthase-catalyzed remethylation of Hcy to methionine, may be another important determinant of Hcy concentrations. Recently, a novel adenine-to-guanine polymorphism (A66G) in MTRR, that converts an isoleucine residue into a methionine at codon 22 , was identified. ${ }^{17}$ The functional significance of this change remains to be determined, although this variant seems to be a risk factor for neural tube defects, especially when the plasma $\mathrm{B}_{12}$ level is low, or when the MTHFR C677T polymorphism is present. ${ }^{17}$ Moreover, women who have both the MTRR 66G and MTHFR 677T mutations appeared to have an increased risk of having a child with Down's syndrome. ${ }^{18,19}$

Our study was performed to explore the presence of a potential link between nutritional deficiencies (vitamin $\mathrm{B}_{12}$ and folate), plasma Hcy levels, C677T, A1298C MTHFR and A66G MTRR polymorphisms in a population of patients with cardiovascular disease. In addition, we also examined the association between the MTHFR and MTRR genotypes and somatic DNA damage measured by MN test, a reliable and sensitive biomarker for evaluating spontaneous and mutagen-induced DNA damage.

\section{Materials and methods Study population}

We studied 68 unrelated adult patients consecutively admitted to the Clinical Cardiology Department of our Institute (CNR, Institute of Clinical Physiology, G Pasquinucci Hospital). Patients exclusion criteria were acute or chronic inflammatory disease, immunological disease and history or presence of neoplastic disease. The medications used by patients included nitrates, oral aspirins, calcium antagonists, angiotensin-converting enzyme inhibitors and diuretics. No patients received vitamin therapy. At the time of blood sampling a complete history, including cardiovascular risk factors such as smoking habits, hypertension, diabetes, dyslipidemia and family history of CAD, was collected from all subjects. Hypertension was defined as blood pressure $>140 / 90 \mathrm{mmHg}$; patients using antihypertensive medication were also classified as hypertensive. Subjects with a history of diabetes or those receiving any antidiabetic medication were considered to be diabetic; subjects were deemed dyslipidemic when their total cholesterol concentration was $\geqslant 220 \mathrm{mg} / \mathrm{dl}$ or their triglyceride concentration was $\geqslant 200 \mathrm{mg} / \mathrm{dl}$, or they were receiving lipid-lowering drugs. Smoking history was coded by grouping patients into those who were nonsmokers and had never smoked, and those who were or had been smokers. A positive family history for CAD was indicated by the presence of a first-degree relative with CAD at the age of $\leqslant 55$ years for men and $\leqslant 65$ years for women. Informed consent was obtained from all the patients according to our ethical committee.

\section{Angiographic study}

All patients underwent coronary angiography. Coronary stenosis was considered significant in the presence of a luminal diameter narrowing of $>50 \%$ in at least one epicardial coronary artery. The severity of CAD was expressed simply by the number of affected vessels (one-, two-, or three-vessel disease).

\section{Measurement of plasma levels of Hcy, vitamin $B_{12}$ and folate \\ Blood was drawn from patients into EDTA tubes after an overnight fasting period of at least $10 \mathrm{~h}$. The plasma levels of Hcy, vitamin $B_{12}$ and folate were assessed by the use of commercially available kits (IMX System, Abbott Labora- tories, Diagnostic Division, Abbott Park, IL, USA). The reference ranges for these methods in our laboratory are the following: Hcy $=4.45-12.42 \mu \mathrm{mol} / \mathrm{l}$; vitamin $\mathrm{B}_{12}=179-1132 \mathrm{pg} / \mathrm{ml}$; folate $=3.1-12.4 \mathrm{ng} / \mathrm{ml}$. Intra-assay and inter-assay coefficients of variation (CVs) were: $\mathrm{Hcy}=1.83 \%$ and $4.33 \%$; vitamin $\mathrm{B}_{12}=4.2 \%$ and $7.4 \%$; folate $=3.8 \%$ and $5.1 \%$, respectively.}

\section{MTHFR and MTRR genotype analyses}

Genomic DNA was extracted from peripheral blood lymphocytes using a standard phenol-chloroform procedure. $^{20}$ The C677T polymorphism in the MTHFR gene was analyzed by polymerase chain reaction (PCR) of genomic DNA by using the following primer pairs: $5^{\prime}$-TGAAGGA GAAGGTGTCTGCGGGA-3' and 5'-AGGACGGTGCGGT GAGAGTG-3'. The C677T mutation creates a Hinfl restric- 
tion site. Digestion of the $198 \mathrm{bp}$ PCR product of 677TT genotype results in two fragments of 175 and $23 \mathrm{bp}$, whereas the 677CC genotype results in one fragment of $198 \mathrm{bp}^{7}$ The second A1298C polymorphism of the MTHFR gene was also analyzed by PCR by using the following primer pairs: 5'-CTTTGGGGAGCTGAAGGACTACTAC-3' and 5'-CACTTTGTGACCATTCCGGTTTG-3'. The amplified fragment of $163 \mathrm{bp}$ was digested with MboII. As the A1298C mutation abolishes an MboII restriction site, digestion of the $163 \mathrm{bp}$ fragment of the 1298AA genotype gives five fragments of $56,31,30,28$ and $18 \mathrm{bp}$, whereas the $1298 \mathrm{CC}$ genotype results in four fragment of $84,31,30$ and $18 \mathrm{bp} .^{12}$ Presence of the MTRR A66G alteration was determined by PCR amplification with the primers $5^{\prime}$-GCAAAGGC CATCGCAGAAGACAT- ${ }^{\prime}$ and 5'-GTGAAGATCTGCA GAAAATCCATGTA-3', where the underlined $\mathrm{C}$ replaces the A to generate an NdeI restriction site in the normal sequence. The PCR fragment of $66 \mathrm{bp}$ remains uncut in the presence of the $66 \mathrm{G}$ allele, but is digested into fragments of 44 and $22 \mathrm{bp}$ in the presence of the $66 \mathrm{~A}$ allele. ${ }^{17}$ After electrophoresis through $12 \%$ polyacrylamide gel, the digestion products were visualized by staining with ethidium bromide.

\section{Lymphocyte preparation and MN assay}

Peripheral blood was collected using heparin as an anticoagulant. Venous blood samples were taken before the angiographic procedure to exclude the effects of X-ray exposure. Cellular cultures from each subject were set up by mixing $0.3 \mathrm{ml}$ of whole blood with $4.7 \mathrm{ml}$ of RPMI 1640 medium (GIBCO), supplemented with $10 \%$ fetal calf serum (GIBCO), 1.5\% phytohemagglutin (PHA; GIBCO) and antibiotics (penicillin $100 \mathrm{IU} / \mathrm{ml}$ and streptomycin $100 \mathrm{mg} / \mathrm{ml}$; Sigma, St Louis, MO, USA). All cultures were incubated at $37^{\circ} \mathrm{C}$ in a humidified atmosphere of $5 \% \mathrm{CO}_{2}$ in air. For evaluation of $\mathrm{MN}$ frequency, cells were blocked in cytokinesis by adding cytochalasin B $(6 \mu \mathrm{g} / \mathrm{ml}$ final concentration; Sigma) after $44 \mathrm{~h}$ of culture. Cell cultures were then harvested at the 72th h. The harvesting of cells, hypotonic treatment, fixation and slide preparation were performed according to previously described methods; ${ }^{21}$ fixed cells were dropped onto clean microscope slides, airdried and stained by the Giemsa technique.

\section{Slide scoring}

For each sample, two microscopists, blinded to patient identity and genetic data, scored 500 binucleated cells on two slides, each slide prepared from one of two different cultures. The slides were scored using an optical microscope (final magnification $\times 400$ ) following the criteria for MN acceptance of Fenech (2000). ${ }^{22}$ MN frequency was expressed as the number of micronucleated binucleated cells (MNBN) containing one or more MN per 1000 cells.

\section{Statistical analysis}

All statistical analyses were conducted using the Statview statistical package, version 5.0. 1, (SAS Institute, Abacus Concepts, Inc., Berkeley, CA, USA). Data were expressed as the mean $( \pm$ SEM) value. Because of the skewed distribution of values for Hcy, folate and vitamin $B_{12}$, analyses were performed using the logarithmic transformation of data. Differences between the means of the two continuous variables were evaluated by Student's $t$-test. Differences in noncontinuous variables and genotype distribution were tested by $\chi^{2}$ analysis. The data for three or more independent groups were investigated by analysis of variance (ANOVA), and significant differences between the pairs of mean values were tested by Scheffe's test. Scheffe's test was chosen for multiple comparisons because it is generally considered to be one of the most conservative tests and also because it is robust to violations of the assumptions typically associated with the multiple comparisons procedure. The relation between two different parameters was obtained by a simple regression analysis. A $P$-value of 0.05 was considered statistically significant.

\section{Results}

Clinical and genetic characteristics of patients

The demographic, clinical and genetic characteristics of the 68 patients are shown in Table 1. Angiographic study revealed that $\mathrm{CAD}$ was present in 51 patients, whereas 17 subjects, examined for reasons other than suspected CAD (mainly valvular heart disease), had normal coronary arteries and neither clinical nor instrumental evidence of atherosclerosis in vascular districts other than the coronary bed. The prevalence of known atherogenic risk factors, such as gender, diabetes, dyslipidemia and family history of CAD, were significantly higher in CAD patients. We determined the C677T, A1298C MTHFR and A66G MTRR genotypes in all our patients. There were no significant differences in the prevalence of the different genotypes between patients with CAD and without CAD. As concerns the polymorphisms of the MTHFR gene, subjects with 677TT homozygous mutant genotype were, without exception, carriers of the homozygous wild-type 1298AA genotype and vice versa, suggesting a complete linkage disequilibrium between the two polymorphisms, as previously observed. ${ }^{12}$

\section{Relation between Hcy, folate and vitamin B12 concentrations}

There was no difference in fasting plasma Hcy, folate and vitamin $B_{12}$ concentrations between the two groups of patients, although plasma levels of Hcy and folate tended to be higher and lower in CAD patients than those in patients without CAD, respectively (Table 1). Moreover, plasma Hcy concentrations were higher in patients with multivessel disease (two- or three-vessel disease) with 
Table 1 Demographic, clinical and genetic characteristics of patients

\begin{tabular}{|c|c|c|c|}
\hline & $\begin{array}{c}\text { No-CAD } \\
(n=17)\end{array}$ & $\begin{array}{c}C A D \\
(n=51)\end{array}$ & $P$ \\
\hline Age, years (mean \pm SEM) & $61.2 \pm 2.9$ & $56.1 \pm 1.1$ & 0.05 \\
\hline Gender (male), $n(\%)$ & $10(58.8)$ & $45(88.2)$ & 0.008 \\
\hline Dyslipidemia & $3(17.6)$ & $41(80.4)$ & $<0.0001$ \\
\hline Hypertension & $7(41.2)$ & $29(56.9)$ & 0.26 \\
\hline Diabetes & 0 & $11(21.6)$ & 0.04 \\
\hline Smokers & $7(41.2)$ & $32(62.7)$ & 0.12 \\
\hline Family history of CAD & $1(5.9)$ & $23(45.1)$ & 0.003 \\
\hline One-vessel & - & $19(37.3)$ & \\
\hline Two-vessels & - & $15(29.4)$ & \\
\hline Three-vessels & - & $17(33.3)$ & \\
\hline MTHFR C677T & & & 0.57 \\
\hline $\mathrm{CC}$ & $5(29.4)$ & $14(27.5)$ & \\
\hline $\mathrm{CT}$ & $10(58.8)$ & $25(49.0)$ & \\
\hline$\pi$ & $2(11.8)$ & $12(23.5)$ & \\
\hline MTHFR A1298C & & & 0.67 \\
\hline $\mathrm{AA}$ & $7(41.2)$ & $27(52.9)$ & \\
\hline $\mathrm{AC}$ & $7(41.2)$ & $18(35.3)$ & \\
\hline $\mathrm{CC}$ & $3(17.6)$ & $6(11.8)$ & \\
\hline MTRR A66G & & & 0.53 \\
\hline $\mathrm{AA}$ & $2(11.8)$ & $12(23.5)$ & \\
\hline AG & $9(52.9)$ & $21(41.2)$ & \\
\hline GG & $6(35.3)$ & $18(35.3)$ & \\
\hline Homocysteine $(\mu \mathrm{mol} / \mathrm{l})$ & $13.7 \pm 1.4$ & $16.5 \pm 1.7$ & 0.62 \\
\hline Folate $(\mathrm{ng} / \mathrm{ml})$ & $5.3 \pm 0.8$ & $4.1 \pm 0.2$ & 0.09 \\
\hline Vit. $B_{12}(\mathrm{pg} / \mathrm{ml})$ & $386.7 \pm 34.9$ & $390.7 \pm 27.4$ & 0.66 \\
\hline
\end{tabular}

respect to monovessel disease and no-CAD patients $(19.4 \pm 2.6$ vs $11.6 \pm 1.2$ and $13.7 \pm 1.4 \mu \mathrm{mol} / \mathrm{l}$, respectively; $P=0.03)$. Again, plasma Hcy levels were inversely and significantly associated with plasma concentrations of folate $(r=-0.236 ; P=0.05)$ and vitamin $\mathrm{B}_{12}(r=-0.288$; $P=0.02$ ) (Figure 1).

Effect of the single C677T, A1298C MTHFR and A66G MTRR polymorphisms on plasma Hcy, folate and vitamin $B_{12}$ levels

As shown in Table 2, there was a highly significant effect of the C677T polymorphism on Hcy levels, with homozygous patients for the thermolabile variant having higher Hcy levels than either of the other two genotype groups $(P=0.004$. and 0.001 for TT $v s$ CC and CT, respectively). Moreover, folate and vitamin $\mathrm{B}_{12}$ levels in patients with 677 TT genotype tended to be lower than in those with the 677CC or 677CT genotypes, although these differences were not statistically significant (Table 2). We found no significant relation between the genotypes of the A1298C polymorphism and Hcy, folate or vitamin $\mathrm{B}_{12}$ levels. As concerns MTRR polymorphism, no associations were observed between any of the MTRR genotypes, Hcy and a

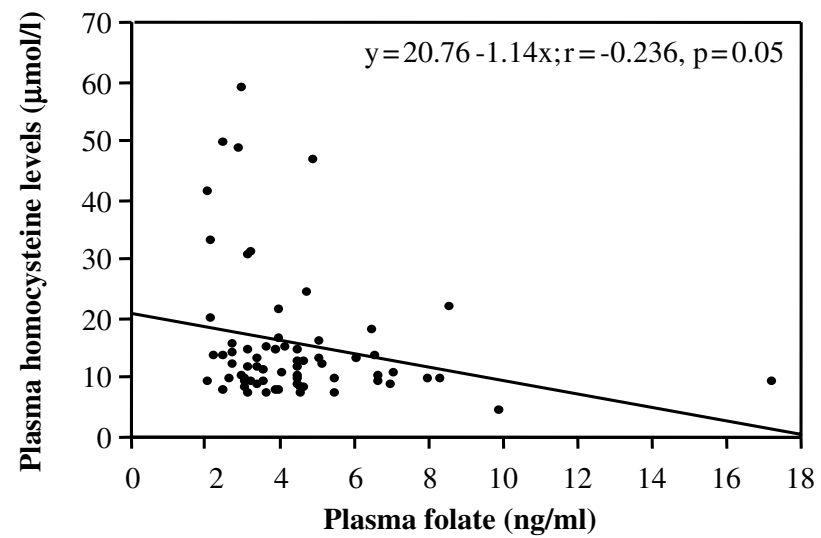

b

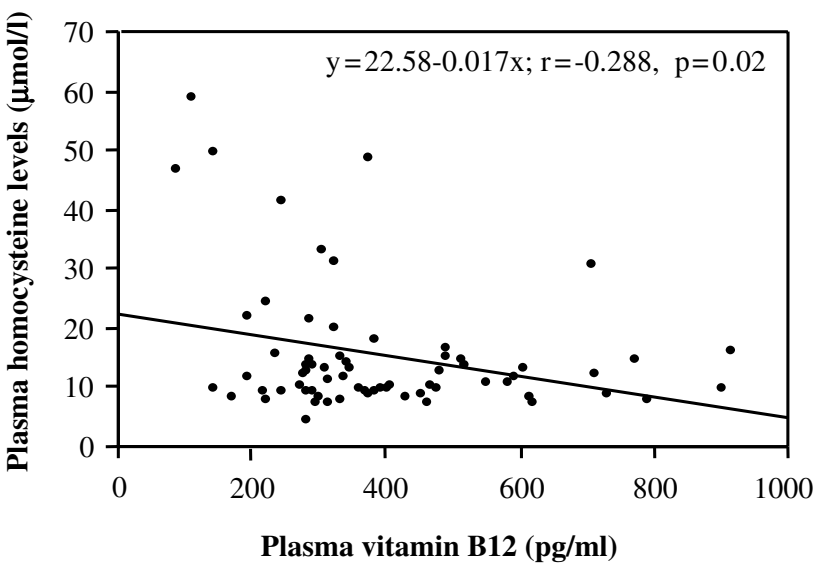

Figure 1 Relation between plasma levels of Hcy and folate (a) and vitamin $B_{12}$ (b).

Table 2 Plasma homocysteine, folate and vitamin $B_{12}$ levels according to C677T and A1298C MTHFR and A66C MTRR genotypes

\begin{tabular}{|c|c|c|c|c|}
\hline & $n$ & Hcy $(\mu \mathrm{mol} / \mathrm{l})$ & Folate $(\mathrm{ng} / \mathrm{ml})$ & Vit. $B_{12}(\mathrm{pg} / \mathrm{ml})$ \\
\hline \multicolumn{5}{|c|}{ MTHFR C677T genotype } \\
\hline CC & 19 & $13.1 \pm 1.4$ & $4.2 \pm 0.4$ & $406.8 \pm 44.3$ \\
\hline $\mathrm{CT}$ & 35 & $13.0 \pm 1.4$ & $4.7 \pm 0.5$ & $408.2 \pm 29.6$ \\
\hline$\pi$ & 14 & $26.2 \pm 4.3^{a}$ & $3.9 \pm 0.5$ & $320.4 \pm 49.9$ \\
\hline \multicolumn{5}{|c|}{ MTHFR A1298C genotype } \\
\hline $\mathrm{AA}$ & 34 & $17.2 \pm 2.2$ & $4.6 \pm 0.5$ & $355.3 \pm 30.7$ \\
\hline$A C$ & 25 & $14.9 \pm 2.1$ & $4.1 \pm 0.3$ & $412.0 \pm 34.6$ \\
\hline $\mathrm{CC}$ & 9 & $12.7 \pm 1.8$ & $4.4 \pm 0.6$ & $457.7 \pm 72.6$ \\
\hline \multicolumn{5}{|c|}{ MTRR A66G genotype } \\
\hline AA & 14 & $20.9 \pm 4.8$ & $3.5 \pm 0.3$ & $326.1 \pm 55.6$ \\
\hline AG & 30 & $13.2 \pm 1.1$ & $4.4 \pm 0.3$ & $442.3 \pm 32.3^{b}$ \\
\hline GG & 24 & $15.9 \pm 2.1$ & $4.9 \pm 0.6$ & $361.2 \pm 33.5$ \\
\hline
\end{tabular}

${ }^{\mathrm{a}} P<0.01 \mathrm{TT}$ vs CT and CC.

${ }^{\mathrm{b}} P<0.05 \mathrm{AG} v \mathrm{vs}$ AA. 
folate concentrations, whereas vitamin $\mathrm{B}_{12}$ levels were lower in 66AA homozygotes compared to 66AG individuals $(P=0.02)$ (Table 2).

Relationship between combined C677T/A1298C and C677T/A66G genotypes and Hcy, folate and vitamin $B_{12}$ levels

To exclude the strong effect of the 677T variant on the plasma Hcy levels, we studied the influence of the A1298C MTHFR and A66G MTRR polymorphisms on the Hcy concentrations only in 677CC wild-type patients. Among these patients, we found no correlation between any of the A1298C genotypes and Hcy concentrations $(9.8 \pm 0.6$, $15.9 \pm 3.5$ and $12.7 \pm 1.8 \mu \mathrm{mol} / \mathrm{l}$ for $1298 \mathrm{AA}, \mathrm{AC}$ and CC, respectively; $P=\mathrm{NS}$ ). Regarding the MTRR polymorphism, 66GG mutant individuals with 677CC wild-type genotype tended to have higher levels of Hcy with respect to 66AA homozygotes $(14.5 \pm 1.9$ vs $8.9 \pm 0.7 \mu \mathrm{mol} / \mathrm{l}, \quad P=0.06)$, although failing to reach statistical significance.

Relation between MN levels and plasma Hcy, folate and vitamin $B_{12}$ levels

With regard to MN assay, we did not find significant correlation between MN frequency and other risk factors, although diabetic and smoker patients had elevated levels of MN (data not shown). There was no correlation between DNA damage and drug therapies. Patients with CAD exhibited higher levels of MN with respect to patients without CAD $(11.0 \pm 0.8$ vs $8.2 \pm 0.9 ; P=0.07)$ and the frequency of $\mathrm{MN}$ in multivessel disease patients increased as compared to monovessel disease and no-CAD subjects $(12.5 \pm 1.1$ vs $8.5 \pm 0.8$ and $8.2 \pm 0.9$, respectively; $P=0.006)$. MN frequency was not significantly correlated with plasma folate $(r=0.109, P=0.37)$, and there was a weakly negative correlation with plasma vitamin $B_{12}$ $(r=-0.235, P=0.054)$. Conversely, $\mathrm{MN}$ frequency and plasma Hcy levels were significantly and positively correlated ( $r=0.33, P=0.006)$ (Figure 2).

\section{Relation between MN levels and C677T, A1298C and A66G genotypes}

We also explored a possible effect of the three genotypes on MN levels. With regard to C677T genotype, MN frequency was significantly higher in subjects with the TT genotype than in those with the CC and CT genotype (14.4 $\pm 2.0 \mathrm{vs}$ $8.8 \pm 1.2$ and $9.5 \pm 0.7$, respectively; $P=0.006$ ) (Figure $3 a$ ). On the contrary, no significant difference was found between $\mathrm{MN}$ frequency and A1298C (11.4 $\pm 1.0,9.3 \pm 0.9$ and $8.8 \pm 2.3$ for $\mathrm{AA}, \mathrm{AC}$ and $\mathrm{CC}$, respectively) and $\mathrm{A} 66 \mathrm{G}$ $(10.1 \pm 1.2,10.0 \pm 0.9$ and $10.8 \pm 1.4$ for $\mathrm{AA}, \mathrm{AG}$ and $\mathrm{GG}$, respectively) genotypes. However, among 677TT homozygous patients, subjects with $677 \mathrm{TT} / 66 \mathrm{GG}$ double mutant genotype tended to have higher levels of $\mathrm{MN}$ when compared to those with 677TT/66AA and 677TT/66AG

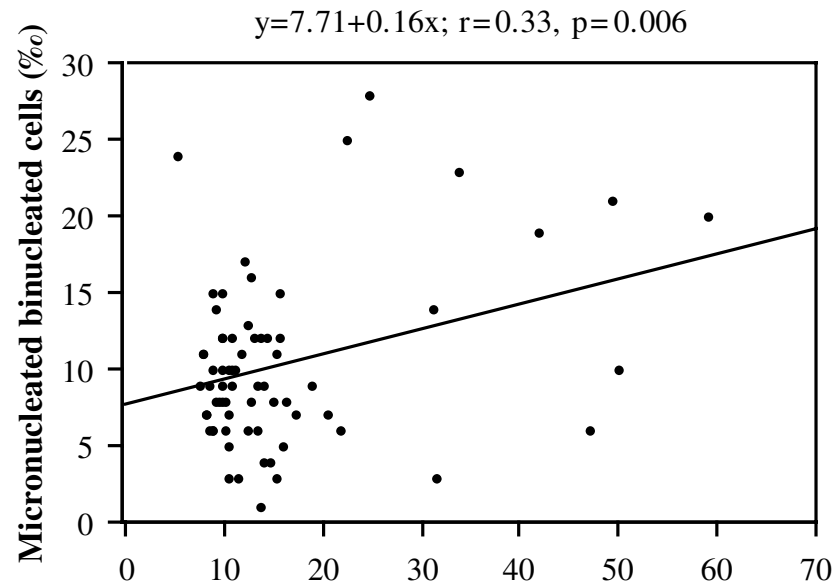

Plasma homocysteine levels $(\mu \mathrm{mol} / \mathrm{l})$

Figure 2 Relation between $\mathrm{MN}$ frequency and plasma levels of Hcy.
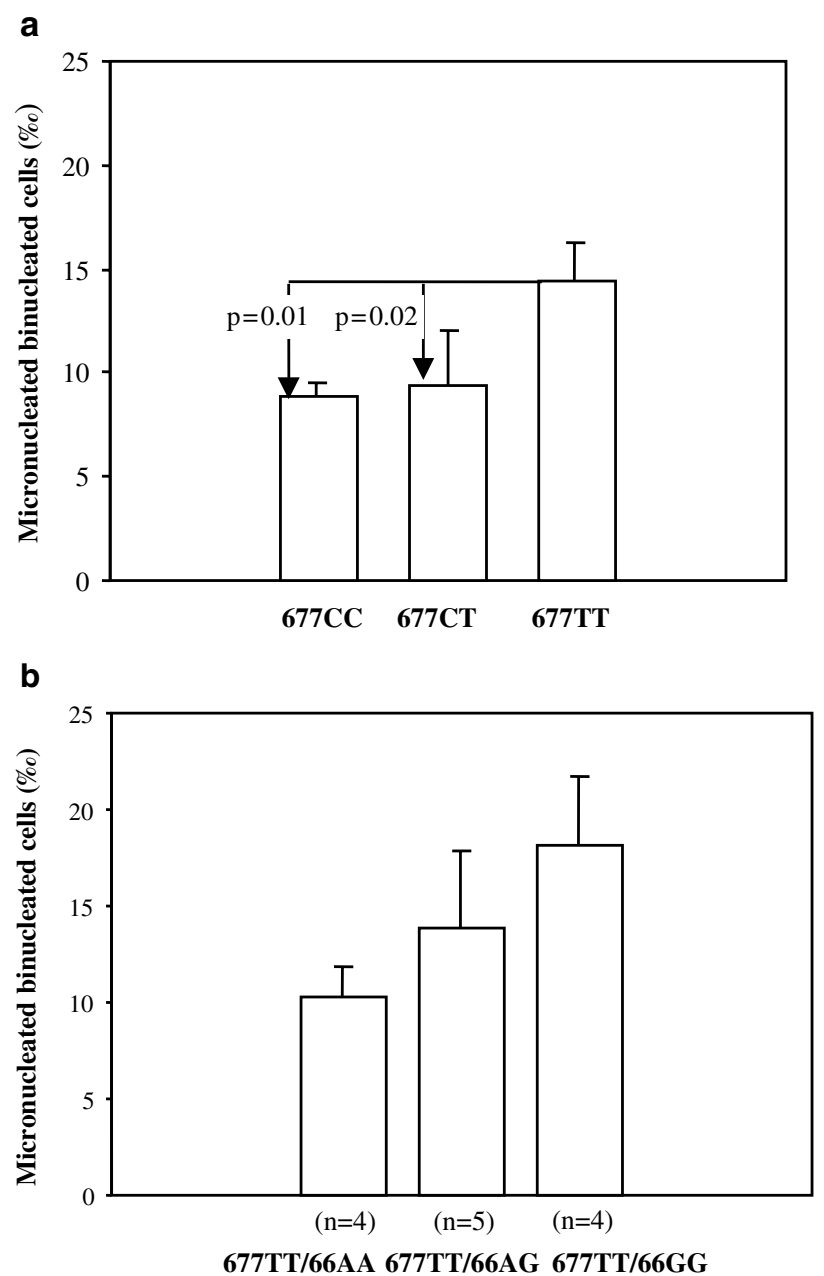

Figure $3 \mathrm{MN}$ frequency in relation to the C677T MTHFR genotypes (a) and to the A66G MTRR genotypes in patients with $677 T$ T genotype (b). 
genotypes $(18.2 \pm 3.6,13.8 \pm 4.0$ and $10.3 \pm 1.7$ for $66 \mathrm{GG}$, AG and AA, respectively; $P=\mathrm{NS}$ ) (Figure $3 \mathrm{~b}$ ).

\section{Discussion}

In this study, we assessed the effect of several polymorphisms on Hcy plasma levels and DNA damage in a population of angiographically characterized cardiovascular patients. It is noteworthy that elevated levels of DNA damage and Hcy correlated with the severity of CAD, as previously reported by our group and others. ${ }^{21,23-25}$ We also confirmed our previous data that homozygosity for the 677T variant was associated with raised plasma Hcy levels. ${ }^{11}$ In accordance with other investigations, a trend towards low levels of folate and vitamin $\mathrm{B}_{12}$ is present in 677TT individuals, confirming the evidence for an important genetic-environmental interaction. ${ }^{26}$ By contrast, when the effect of the A1298C polymorphism was examined, no effect on levels of Hcy, vitamin $B_{12}$ or folate was seen in our population. No correlation was also observed between combined heterozygotes for both MTHFR polymorphisms and plasma Hcy levels. Indeed, some studies demonstrated that subjects who were double heterozygotes, 677CT/1298AC, have significantly increased plasma total Hcy concentrations. ${ }^{12,13}$ However, other recent investigations suggested that this polymorphism might not significantly affect Hcy metabolism, in accordance with our results. ${ }^{16,27}$

When the effect of the A66G polymorphism in the MTRR gene on levels of Hcy was examined, no difference was seen between the genotypes. However, when the relation was analyzed without the confounding effect of the 677T variant, the $66 \mathrm{G}$ variant seemed to have a weak influence on Hcy levels. The functional significance of this polymorphism remains to be determined. Conflicting data have appeared in the literature concerning the association of the A66G polymorphism and Hcy levels. Only one report shows an association between elevated plasma Hcy levels and 66GG genotype in healthy men population. ${ }^{28}$ Other reports have failed to demonstrate any correlation between Hcy and MTRR genotype. ${ }^{17,19,29}$ However, the 66GG genotype seems to be correlated with an increased risk for the development of premature CAD. ${ }^{29}$

Hyperhomocysteinemia has been identified as an independent risk factor for cerebral, coronary and peripheral atherosclerosis, ${ }^{2}$ by putative mechanisms including endothelial dysfunction, increased platelet adhesion, and proliferation of vascular smooth muscle cells. ${ }^{30}$ Moreover, several studies have also shown that Hcy can induce DNA damage and, in particular, that plasma Hcy levels are positively correlated with micronucleus frequency in human lymphocytes. ${ }^{31,32}$ Indeed, elevated levels of Hcy may induce DNA damage either by an increased production of reactive oxygen species or by biological mechanisms directly associated with an excessive misincorporation of uracil in DNA and the process of DNA methylation (Figure 4). ${ }^{33-39}$

Hcy seems to promote atherogenesis by means of generating potent reactive oxygen species (ie hydrogen peroxide and superoxide anion radical) and, thus, an increased production of reactive oxygen species may also be involved in Hcy-mediated DNA damage. ${ }^{39,40}$ Furthermore, folate deficiency can induce an excessive misincorporation of uracil in DNA resulting in some genetic alterations including point mutation, chromosome breaks and micronucleus formation. ${ }^{35,39}$ In addition, global DNA hypomethylation may induce chromosome loss probably because of the undercondensation of pericentromeric heterochromatin and it is known that chromosome loss leads to micronucleus formation and aneuploidy. ${ }^{35}$ Indeed, experimental studies have demonstrated that hypomethylation of DNA in the centromeric regions of chromosomes $1,9,15,16$ and $\mathrm{Y}$ leads to despiralization and faulty kinetocore assembly, inducing the specific loss of these chromosomes as micronuclei. ${ }^{41}$ Interestingly, these aneuploides have been observed in ICF immunodeficiency syndrome, which is caused by mutation in the DNA methyl transferase. ${ }^{42}$

The maintenance of normal DNA methylation is crucial for normal gene expression, genomic imprinting, and cellular differentiation. ${ }^{33,35}$ Alterations in DNA methylation are well characterized in human cancers, however this process may play an important role also in atherogenesis. Interestingly, it has been hypothesized that hypomethylation of the DNA by upregulating atherosclerosis-susceptible genes and downregulating atherosclerosis-protective genes may be an important contributor leading to the formation of atheroma. ${ }^{36}$ Notably, a recent study showed that genomic hypomethylation occurs during atherosclerosis in human, mouse and rabbit lesions and that it correlates with increased transcriptional activity, in particular of the proto-oncogene platelet-derived growth factor B (PDGF-B) that can induce smooth muscle cells proliferation. ${ }^{43}$ Moreover, a marked hypomethylation of the extracellular superoxide dismutase (ec-sod) gene, that protects arteries against deleterious effects of superoxide anions and the development of atherosclerosis, was detected in rabbit atherosclerotic lesions. ${ }^{44}$ Thus, MTHFR and MTRR, which are involved in the pathway that provides methyl groups for DNA methylation, may alter methylation reactions leading to DNA hypomethylation. Most importantly, human studies show that the 677TT variant is associated with genomic DNA hypomethylation. ${ }^{45,46}$

In this study, we showed that homozygosity for the common 677T mutation in the MTHFR gene is associated with higher levels of MN frequency. Interestingly, individuals with combined homozygosity for the two variants, 677T in MTHFR and 66G in MTRR gene, resulted in more elevated levels of Hcy and DNA damage, suggesting a 


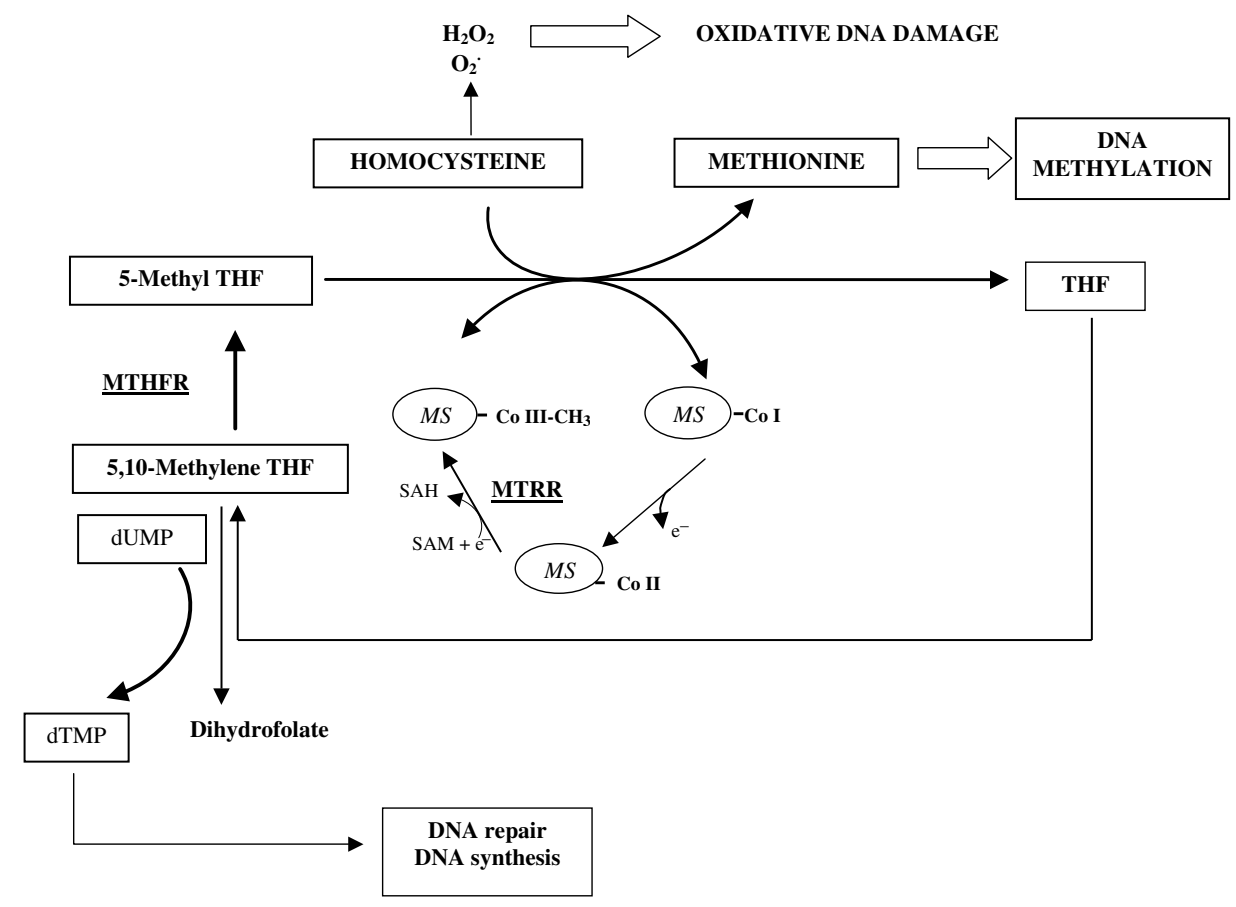

Figure 4 Possible mechanisms of DNA damage in homocysteine metabolism may include the generation of reactive oxygen species, a decrease in the synthesis of thymidylate (dTMP) with accumulation of dUMP and incorporation of uracil into DNA instead of thymine, and/or alterations in the normal maintenance of DNA methylation. THF, tetrahydrofolate. MS, methionine synthase. Co, cobalamin. SAM, S-adenosylmethionine. SAH, S-adenosylhomocysteine.

probable interaction between the two mutations. This observation is of particular interest in relation to several studies providing evidence that the maternal genotypes for MTHFR and MTRR are associated with the risk of neural tube defects. ${ }^{17}$ In particular, the 66GG genotype, when combined with low cobalamin levels, appeared to increase the risk for giving birth to a child with neural tube defects, and the presence of two mutant genotypes, MTRR 66GG and MTHFR 677TT, conferred a greater risk than either genotype alone. ${ }^{17}$ Again, the combined presence of both mutations appeared to increase the risk of producing offspring with Down's syndrome. ${ }^{18,19}$

Taken together, these observations suggest that elevated plasma Hcy levels, derived by nutritional deficiencies and MTHFR variants and/or other polymorphisms in the genes involved in its metabolism, for example, MTRR, may be important determinants of genetic instability in several diseases, including atherosclerosis.

Larger and heterogeneous study populations are necessary to quantify the small effects of common mutations on homocysteine levels and DNA damage. However, although the observation of our study is based on relatively few individuals, it is of particular interest and suggests a possible link between homocysteine and genetic instability in humans.

\section{References}

1 McCully KS: Chemical pathology of homocysteine. II. Carcinogenesis and homocysteine thiolactone metabolism. Ann Clin Lab Sci 1994; 24: 27-59.

2 Fonseca V, Guba SC, Fink LM: Hyperhomocysteinemia and the endocrine system: implications for atherosclerosis and thrombosis. Endocr Rev 1999; 20: 738-759.

3 Breteler MM: Vascular involvement in cognitive decline and dementia. Epidemiologic evidence from the Rotterdam Study and the Rotterdam Scan Study. Ann NY Acad Sci 2000; 903: 457-465.

4 Miller JW: Homocysteine, Alzheimer's disease, and cognitive function. Nutrition 2000; 16: 675-677.

5 Wenstrom KD, Johanning GL, Owen J, Johnston KE, Acton S, Tamura T: Role of amniotic fluid homocysteine level and of fetal 5,10-methylenetetrahydrafolate reductase genotype in the etiology of neural tube defects. Am J Med Genet 2000; 90: 12-16.

6 Kang SS, Wong PW, Susmano A, Sora J, Norusis M, Ruggie N: Thermolabile methylenetetrahydrofolate reductase: an inherited risk factor for coronary artery disease. Am J Hum Genet 1991; 48: 536-545.

7 Frosst P, Blom HJ, Milos R et al: A candidate genetic risk factor for vascular disease: a common mutation in methylenetetrahydrofolate reductase. Nat Genet 1995; 10: 111-113.

8 Jacques PF, Bostom AG, Williams RR et al: Relation between folate status a common mutation in methylenetetrahydrofolate reductase, and plasma homocysteine concentrations. Circulation 1996; 93: 7-9.

9 Christensen B, Frosst P, Lussier-Cacan S et al: Correlation of a common mutation in the methylenetetrahydrofolate reductase gene with plasma homocysteine in patients with premature coronary artery disease. Arterioscler Thromb Vasc Biol 1997; 17: 569-573. 
10 Brattstrom L, Wilcken DE, Ohrvik J, Brudin L: Common methylenetetrahydrofolate reductase gene mutation leads to hyperhomocysteinemia but not to vascular disease: the result of a meta-analysis. Circulation 1998; 98: 2520-2526.

11 Andreassi MG, Botto N, Cocci F et al: Methylentetrahydrofolate reductase gene C677T polymorphism, homocysteine, vitamin B12 and DNA damage in coronary artery disease. Hum Genet 2003; 112: 171-177.

12 van der Put NM, Gabreels F, Stevens EM et al: A second common mutation in the methylenetetrahydrofolate reductase gene: an additional risk factor for neural-tube defects. Am J Hum Genet 1998; 62: 1044-1051.

13 Weisberg I, Tran P, Christensen B, Sibani S, Rozen R: A second genetic polymorphism in methylenetetrahydrofolate reductase (MTHFR) associated with decreased enzyme activity. Mol Genet Metab 1998; 64: 169-172.

14 Chango A, Boisson F, Barbe F et al: The effect of $677 \mathrm{C} \rightarrow \mathrm{T}$ and $1298 \mathrm{~A} \rightarrow \mathrm{C}$ mutations on plasma homocysteine and 5,10methylenetetrahydrofolate reductase activity in healthy subjects. Br J Nutr 2000; 83: 593-596.

15 Hanson NQ, Aras O, Yang F, Tsai MY: C677T and A1298C polymorphisms of the methylenetetrahydrofolate reductase gene: incidence and effect of combined genotypes on plasma fasting and post-methionine load homocysteine in vascular disease. Clin Chem 2001; 47: 661-666.

16 Friso S, Girelli D, Trabetti E et al: A1298C methylenetetrahydrofolate reductase mutation and coronary artery disease: relationships with C677T polymorphism and homocysteine/ folate metabolism. Clin Exp Med 2002; 2: 7-12.

17 Wilson A, Platt R, Wu Q et al: A common variant in methionine synthase reductase combined with low cobalamin (vitamin B12) increases risk for spina bifida. Mol Genet Metab 1999; 67: 317-323.

18 Hobbs CA, Sherman SL, Yi P et al: Polymorphisms in genes involved in folate metabolism as maternal risk factors for Down syndrome. Am J Hum Genet 2000; 67: 623-630.

19 O'Leary VB, Parle-McDermott A, Molloy AM et al: MTRR and MTHFR polymorphism: link to Down syndrome? Am J Med Genet 2002; 107: 151-155.

20 Sambrook J, Fritsch EF, Maniatis T (eds): Molecular cloning: a laboratory manual, 2nd edn. Cold Spring Harbor, NY: Cold Spring Harbor Laboratory, 1989.

21 Botto N, Rizza A, Colombo MG et al: Evidence for DNA damage in patients with coronary artery disease. Mutat Res 2001; 493: 23-30.

22 Fenech M. The in vitro micronucleus technique. Mutat Res 2000; 455: 81-95.

23 Van Schooten FJ, Hirvonen A, Maas LM et al: Putative susceptibility markers of coronary artery disease: association between VDR genotype, smoking, and aromatic DNA adduct levels in human right atrial tissue. FASEB J 1998; 12: 1409-1417.

24 Tribouilloy CM, Peltier M, Iannetta Peltier MC, Trojette F, Andrejak M, Lesbre JP: Plasma homocysteine and severity of thoracic aortic atherosclerosis. Chest 2000; 118: 1685-1689.

25 Schnyder G, Pin R, Roffi M, Flammer Y, Hess OM: Association of plasma homocysteine with the number of major coronary arteries severely narrowed. Am J Cardiol 2001; 88: 1027-1030.

26 Ueland PM, Hustad S, Schneede J, Refsum H, Vollset SE: Biological and clinical implications of the MTHFR C677T polymorphism. Trends Pharmacol Sci 2001; 22: 195-201.

27 Friedman G, Goldschmidt N, Friedlander Y et al: A common mutation A1298C in human methylenetetrahydrofolate reductase gene: association with plasma total homocysteine and folate concentrations. J Nutr 1999; 129: 1656-1661.

28 Gaughan DJ, Kluijtmans LA, Barbaux S et al: Corrigendum to 'The methionine synthase reductase (MTRR) A66G polymorphism is a novel genetic determinant of plasma homocysteine concentrations'. Atherosclerosis (in press).

29 Brown CA, McKinney KQ, Kaufman JS, Gravel RA, Rozen R: A common polymorphism in methionine synthase reductase increases risk of premature coronary artery disease. J Cardiovasc Risk 2000; 7: 197-200.

30 Thambyrajah J, Townend JN: Homocysteine and atherothrombosis - mechanisms for injury. Eur Heart J 2000; 21: 967-974.

31 Fenech MF, Dreosti IE, Rinaldi JR: Folate, vitamin B12, homocysteine status and chromosome damage rate in lymphocytes of older men. Carcinogenesis 1997; 18: 1329-1336.

32 Fenech M, Aitken C, Rinaldi J: Folate, vitamin, B12 homocysteine status and DNA damage in young Australian adults. Carcinogenesis 1998; 19: 1163-1171.

33 Yi P, Melnyk S, Pogribna M, Pogribny IP, Hine RJ, James SJ: Increase in plasma homocysteine associated with parallel increases in plasma $S$-adenosylhomocysteine and lymphocyte DNA hypomethylation. J Biol Chem 2000; 275: 29318-29323.

34 Crott J, Fenech M: Preliminary study of the genotoxic potential of homocysteine in human lymphocytes in vitro. Mutagenesis 2001; 16: 213-217.

35 Fenech M: The role of folic acid and Vitamin B12 in genomic stability of human cells. Mutat Res 2001; 475: 57-67.

36 Dong C, Yoon W, Goldschmidt-Clermont PJ: DNA methylation and atherosclerosis. J Nutr 2002; 132: 2406S-2409S.

37 Duthie SJ, Narayanan S, Brand GM, Pirie L, Grant G: Impact of folate deficiency on DNA stability. I Nutr 2002; 132: 2444S-2449S.

38 Friso S, Choi SW: Gene-nutrient interactions and DNA methylation. J Nutr 2002; 132: 2382S-2387S.

39 Andreassi MG: Coronary atherosclerosis and somatic mutations: an overview of the contributive factors for oxidative DNA damage. Mutat Res 2003; 543: 67-86.

40 Loscalzo J: The oxidant stress of hyperhomocyst(e)inemia. J Clin Invest 1996; 98: 5-7.

41 Guttenbach M, Schmid M: Exclusion of specific human chromosomes into micronuclei by 5-azacytidine treatment of lymphocyte cultures. Exp Cell Res 1994; 211: 127-132.

$42 \mathrm{Xu}$ GL, Bestor TH Bourc'his D et al: Chromosome instability and immunodeficiency syndrome caused by mutations in a DNA methyltransferase gene. Nature 1999; 402: 187-191.

43 Hiltunen MO, Turunen MP, Hakkinen TP et al: DNA hypomethylation and methyltransferase expression in atherosclerotic lesions. Vasc Med 2002; 7: 5-11.

44 Laukkanen MO, Mannermaa S, Hiltunen MO et al: Local hypomethylation in atherosclerosis found in rabbit ec-sod gene. Arterioscler Thromb Vasc Biol 1999; 19: 2171-2178.

45 Stern LL, Mason JB, Selhub J, Choi SW: Genomic DNA hypomethylation, a characteristic of most cancers, is present in peripheral leukocytes of individuals who are homozygous for the C677T polymorphism in the methylenetetrahydrofolate reductase gene. Cancer Epidemiol Biomarkers Prev 2000; 9: 849-853.

46 Friso S, Choi SW, Girelli D et al: A common mutation in the 5,10methylenetetrahydrofolate reductase gene affects genomic DNA methylation through an interaction with folate status. Proc Natl Acad Sci USA 2002; 99: 5606-5611. 